\title{
Relationship of heat wave and dietary factors on high blood pressure in hypertensive female population under extreme weather conditions
}

\author{
Ayesha Riaz ${ }^{1 *}$, Anika Ubaid ${ }^{2}$, Muhammad Ahsan Riaz ${ }^{3}$, Madiha Ilyas ${ }^{4}$ \\ and Sadaf Nazar ${ }^{1}$ \\ 1. Department of Zoology, GC Women University Faisalabad-Pakistan \\ 2. Institute of Molecular Biology and Biotechnology, The University of Lahore, Lahore-Pakistan \\ 3. Department of Environmental Sciences and Engineering, Government College University Faisalabad-Pakistan \\ 4. Department of Home Economics and Food Sciences, GC Women University Faisalabad-Pakistan \\ *Corresponding author's email: ayeshariazrana@googlemail.com \\ Citation \\ Ayesha Riaz, Anika Ubaid, Muhammad Ahsan Riaz, Madiha Ilyas and Sadaf Nazar. Relationship of heat wave and \\ dietary factors on high blood pressure in hypertensive female population under extreme weather conditions. Pure \\ and Applied Biology. Vol. 9, Issue 1, pp275-281. http://dx.doi.org/10.19045/bspab.2020.90032
}

\begin{tabular}{llll}
\hline \hline Received: 20/07/2019 & Revised: 19/09/2019 & Accepted: 01/10/2019 & Online First: 23/10/2019 \\
\hline \hline
\end{tabular}

\section{Abstract}

Seasonal effects on blood pressure variations related diseases have been studied in several populations. The study has been conducted to examine the blood pressure fluctuations and dietary factors in the elderly population under extreme weather conditions. The association of blood pressure in relation to serum profile and outdoor temperature was examined in one hundred and sixteen young systemic hypertension female subjects in our study that previously diagnosed as hypertensive. Subjects were evaluated for fasting serum cholesterol profiles and observed that there was a significant difference in serum cholesterol levels among these two groups (pre-high blood pressure group (175.6 \pm 4.26$)$ versus high blood pressure group $(206.16 \pm 5.48)$. We observed the effects of vegetarian and non-vegetarian diet on high blood pressure among the hypertensive female population. A significant difference was observed in systolic blood pressure (140.75 \pm 1.84$)$

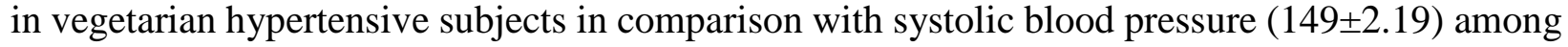
non-vegetarian hypertensive study group. Similarly, effect of vegetarian and non-vegetarian diet on diastolic blood pressure was also studied. A significant difference in diastolic blood pressure was also observed among vegetarians (87.93 \pm 0.88$)$ and non-vegetarian group $(92.16 \pm 1.12)$ under extreme temperature conditions. We observed that the increase in serum cholesterol level and outdoor temperature is directly related to elevation in hypertension ratio noticed that high temperature affects hypertensive content in female population who also exhibited elevated serum cholesterol profile. Similarly a high blood pressure ratio was observed among non-vegetarians as compared to vegetarian group. The current study emphasizes that dietary pattern modifications are probably one of the most important tools for effective lowering of high blood pressure.

Keywords: Heatwave; Hypertension; Metabolic disorders; Non-vegetarians Serum cholesterol level; Systolic blood pressure 


\section{Introduction}

Intra-individual seasonal blood pressure variation has been described in many populations. Studies suggested weather associated variations of blood pressure in adult populations [1-4]. Arterial blood pressure fluctuations with increasing outdoor temperature have been described in both normotensive [3] and hypertensive populations [5], as well as in renal disease end-stage patients [6]. Recently, a heatwave in Moscow caused around 11,000 causalities [7]. Pakistan is also facing the urban island effect in major cities and worst flooding of its history. Very recently, the deadliest heatwave caused of 1200 death in Pakistan whichcan be attributed to climate changes. The continuous increase in duration, intensity, and magnitude of future heatwaves due to global warming has adverse health effect on the local population $[8,9]$.

Food and its components play an important role in regulation of salt and electrolyte profile of an individual, which may be one of the important regulatory factors in the prevention of hypertension and its related morbidity. It has been reported that the vegetarian populations have lower blood pressure, serum and urinary sodium chloride and body weight than non-vegetarian, but there is a strong possibility that effect of diet may be confounded by other lifestyle factors $[10,11]$. Lifestyle modifications should be the first treatment for hypertension patients [12]. The vegetarian diet has an effective prophylactic to a number of metabolic diseases in the adult population [13]. Although these modifications might not be controlling the blood pressure adequately but may affect the number and doses of medications in a hypertensive population [14].

Hypertension is one of the major health risks among metabolic disorders in Pakistani population. In the present study, we investigated the relationship between serum cholesterol level in hypertensive and nonhypertensive female subjects and also studied the effects of vegetarian and non-vegetarian diet on hypertension under extreme weather conditions in general female population of Pakistan.

\section{Materials and methods}

The present study is a hospital-based study conducted from 2013 to 2014 in Pakistan. Prior to study, a consent form was signed by each participant and standard Performa was prepared. We included one hundred and sixteen young systemic hypertension female subjects in our study that previously diagnosed as hypertensive. Subjects were evaluated for fasting serum cholesterol profile. Serum cholesterol level measured on an automated analyzer at wavelength of 546 $\mathrm{nm}$. In order to study the effect of vegetarian and non-vegetarian diet on hypertension, we included one hundred and sixteen systemic hypertension females' subjects in our study. Blood pressure measurement was done at 5 different intervals by taking readings in triplicates from the female subjects who were purely vegetarian as well as those who were non-vegetarian to observe a relative change in systolic as well as diastolic blood pressure. Data about temperature and atmospheric pressure for the period June 2014 were collected from the Lahore Meteorological Office, Lahore. Statistical data analysis was carried out using an unpaired student t-test on the computer software GraphPad Prism version 6.03 for Windows, Graph Pad Software, San Diego California USA, and www. graphpad.com. Results with $\mathrm{P}<0.05$ were considered to be statistically significant [15].

\section{Results}

We compared the serum cholesterol levels among female hypertensive patients. As per JNC 7 criteria, one group had stage I hypertension differentiated as "pre-high blood pressure group" while the rest had stage II hypertension categorized as the "high 
blood pressure group". There was a significant difference in serum cholesterol levels among these two groups (pre-high blood pressure group; 175.6 \pm 4.26 versus high blood pressure group; 206.16 \pm 5.48 ) as shown in figure 1.

Systolic blood pressure among vegetarians and non-vegetarians

A significant difference was observed in systolic blood pressure $(140.75 \pm 1.84)$ in vegetarian hypertensive subjects in comparison with systolic blood pressure

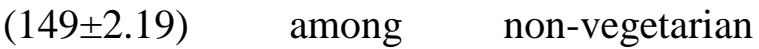
hypertensive study group as shown in figure 2.

Diastolic blood pressure among vegetarians and non-vegetarians

Effect of vegetarian and non-vegetarian diet on diastolic blood pressure was also studied. A significant difference in diastolic blood pressure was noticed among vegetarians $(87.93 \pm 0.88)$ and non-vegetarian group $(92.16 \pm 1.12)$ as shown in figure 3 .

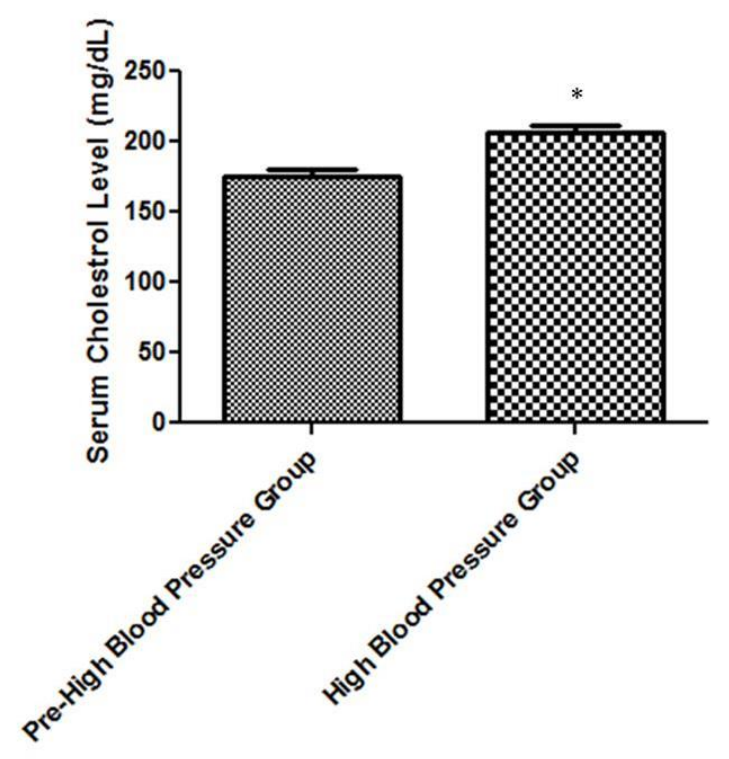

Figure 1. Effect of Serum Cholesterol on high blood pressure

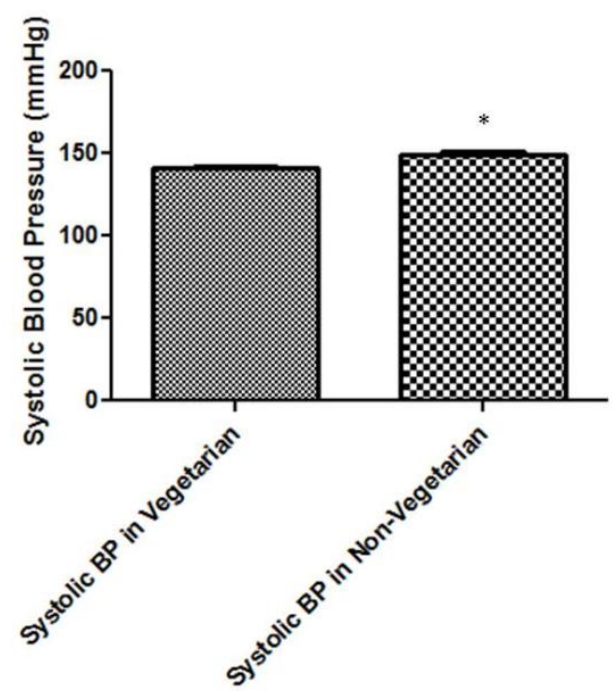

Figure 2. Effect of vegetarian and non-vegetarian diet on systolic blood pressure 


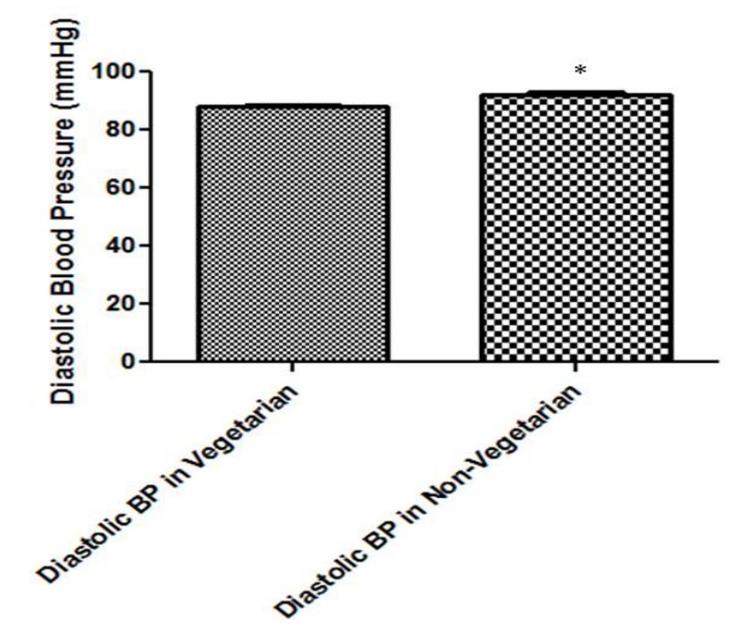

Figure 3. Effect of vegetarian and non-vegetarian diet on Diastolic blood pressure

\section{Discussion}

Effect of outdoor temperature on seasonal variations of blood pressure has been studied for many years. However, most studies involved small or medium-sized samples with repeated measurements of blood pressure among selected individuals [4]. Studies have also investigated the major factors contributing to blood pressure fluctuations and changing weather conditions. In about 100 normotensive aged men (above 50 years), seasonal variations in blood pressure were associated with dietary contents [14, 16]. In August 2003, an unprecedented heatwave in France resulted in about 15000 causalities in the elderly population. This heatwave affected the blood pressure of the Study participants with seasonal fall of the blood pressure values (mean SBP, $132 \mathrm{~mm} \mathrm{Hg}$ ) in August 2003, then, for example, in August 2004 (138mmHg). An increased mortality rate has also been noticed due to environmental hyperthermia as a risk factor for lowering blood pressure [17], showing the importance of blood pressure monitoring in the elderly population under extreme weather conditions. However, the mechanisms explaining the effect of high temperature on blood pressure remain undetermined. Secretion of catecholamine and increased activation of the sympathetic nervous system in response to cold temperatures also results in an increase in blood pressure. Increased heart rate and peripheral vascular resistance have been noticed due to hyperthermia and low blood pressure [18]. Endotheliumdependent mechanisms and vasodilation have also been suggested in association with blood pressure fluctuations in the hypertensive population [19].

Our study found any impact of seasonal temperature variations in hypertension female population. We determined the serum cholesterol level of young female hypertensive patients and observed the relationship between hypertension and serum cholesterol level. We noticed a high ratio of hypertension among subjects with elevation in serum cholesterol level indicated that serum cholesterol level directly affects the blood pressure values in the female population. It has been reported that high serum cholesterol level affects the endothelium might be influencing hypertension in female population [20]. The parallel increase in serum cholesterol level has been studied among hypertensive 
patients. Cholesterol levels caused fluctuation in blood pressure in response to adrenergic stimulation as well [21]. It has been shown previously that the serum cholesterol levels and the dietary habits influenced serum cholesterol levels in adult population. The non-vegetarians had a high level of serum cholesterol as compared to those who were vegetarians [22]. Flesheating habits were significantly associated with high cholesterol level in female population [23].

The present study also revealed high serum cholesterol level in pre-high blood pressure group as compared to high blood pressure group. The present study revealed that systolic blood pressure increased among nonvegetarians but among vegetarians, there was significant reduction in systolic blood pressure. The current study also assessed the diastolic blood pressure among vegetarians and non-vegetarians. There was decrease in diastolic blood pressure among vegetarians while its level increased among nonvegetarians. Our data was in consistence as reported previously [24, 25]. Dietary Approaches to Stop Hypertension (DASH) demonstrated that a diet rich in fruits, vegetables, low-fat dairy products, fiber, and minerals produces a potent antihypertensive effect $[26,27]$ that we also observed in our current study. Our data were in line with Appel et al., who demonstrated that hypertensive's with high dietary fat consumption show high plasma lipid profiles and serum cholesterol. Lifestyle modifications might be the first treatment for patients with mild hypertension [28]. These modifications although not directly control the blood pressure but might reduce the number and doses of medications.

\section{Conclusion}

In conclusion, changes in dietary patterns do affect blood pressure in patients with hypertension. Among hypertension patients, control of blood pressure is necessary in order to reduce cardiovascular morbidity and mortality rate. Lifestyle modifications are probably one of the most important tools for effective lowering of high blood pressure. Outdoor temperature is strongly correlated with blood pressure variations in hypertensive, especially in those with high serum cholesterol profile. During extreme weather conditions, a careful antihypertensive treatment may contribute to lowering the consequences of high blood pressure in hypertensive patients. Considering an increase in future heatwave frequencies, there is a dire need to forecast such events at equitable lag-time. Similarly, the disaster management authority capacities should be improved to address such calamities in future. Education of people at the heart of reducing casualties in terms of maintaining adequate level of hydration, avoiding large protein-rich dietary contents, avoiding unnecessary visits in the sun, etc can result in reduced metabolic heat and metabolic disorders, especially high blood pressure.

\section{Authors' contributions}

Conceived and designed the experiments: A Riaz, Performed the experiments: A Ubaid, Analyzed the data: MA Riaz, Contributed materials/ analysis/ tools: A Riaz, Wrote the paper: A Riaz, M Ilyas \& S Nazar.

\section{References}

1. Rose G (1961). Seasonal variation in blood pressure in man. Nat 189: 235.

2. Nayha S (1985). Adjustment of blood pressure data by season. Scand $J$ Prim Health Care 3(2): 99-105.

3. Imai Y, Munakata M, Tsuji I, Ohkubo T, Satoh H, Yoshino H \& Abe K (1996). Seasonal variation in blood pressure in normotensive women studied by home measurements. Clin Sci 90(1): 55-60.

4. Poumadere M, Mays C, Le Mer S \& Blong R (2005). The 2003 heat wave in France: dangerous climate change here and now. Risk Anal: An Official 
Publication of the Society for Risk Analysis 25(6): 1483- 1494.

5. Kunes J, Tremblay J, Bellavance F \& Hamet P (1991). Influence of environmental temperature on the blood pressure of hypertensive patients in Montreal. Am J Hypertens 4(5): 422426.

6. Argile SA, Mourad G \& Mion C (1998). Seasonal changes in blood pressure in patients with end-stage renal disease treated with hemodialysis. New Eng $J$ Med 339(19): 1364-1370.

7. Shaposhnikov D, Revich B, Bellander T, Bedada GB, Bottai M, Kharkova T \& Pershagen G (2014). Mortality related to air pollution with the Moscow heatwave and wildfire of 2010. Epidemiol 25(3): 359-364.

8. Woodhouse PR, Khaw KT\& Plummer M (1993). Seasonal variation of blood pressure and its relationship to ambient temperature in an elderly population. $J$ Hypertension 11(11): 1267-1274.

9. IPCC (2013). Summary for Policymakers. In: Climate Change 2013: The Physical Science Basis. Contribution of Working Group I to the Fifth Assessment Report of the Intergovernmental Panel on Climate Change. In: Stocker, TF, D Qin, GK Plattner, M Tignor, SK Allen, J Boschung, A Nauels, Y Xia, V Bex and PM Midgley (eds.). Cambridge University Press, Cambridge, United Kingdom and New York, NY, USA, pp. 1-30.

10. Ferrara LA, Guida L, Iannuzzi R, Celentano A \& Lionello F (2002). Serum cholesterol affects blood pressure regulation. J Hum Hypertension16: 337343.

11. Johnson AG, Nguyen TV \& Davis D (2001). Blood pressure is linked to salt intake and modulated by the angiotensinogen gene in normotensive and hypertensive elderly subjects. $J$ Hypertension. 19: 1053-1060.

12. Bonaa HK \& Thelle DS (1991). Association between blood pressure and serum lipids in apopulation. TheTromso study. J Circulation 83: 1305-1314.

13. Osuji CU, Omejua EG, Onwubuya EI \& Ahaneku GI (2012). Serum lipid profile of newly diagnosed hypertensive patients in Nnewi, South East Nigeria. Int J Hypertension 1155(10): 710486.

14. Satish S, Zhang DD \& Goodwin JS (2001). Clinical significance of falling blood pressure among older adults. $J$ Clin Epidemiol 54(9): 961-967.

15. GraphPad Prism version 6.04 for Windows, GraphPad Software, La Jolla California USA, www.graphpad.com".

16. LoVecchio F, Pizon AF, Berrett $\mathrm{C}$ \& Balls A (2007). Outcomes after environmental hyperthermia. Am $J$ Emerg Med 25(4): 442-444.

17. Hanna JM (1999). Climate, altitude, and blood pressure. Hum Bio 71(4): 553-582.

18. Widlansky ME, Vita JA \& Keyes MJ et al. (2007). Relation of season and temperature to endothelium-dependent flow-mediated vasodilation in subjects without clinical evidence of cardiovascular disease (from the Framingham Heart Study). Am J Cardiol 100(3): 518-523.

19. Kristal-Boneh E, Harari G \& Green MS (1997). Seasonal change in 24-hour blood pressure and heart rate is greater among smokers than nonsmokers. $J$ Hypertension 30(3): 436-441.

20. Appel LJ, Brand MW, Daniels SR, Karanja N, Elmer PJ \& Sacks FM (2006). Dietary Approaches to Prevent and Treat Hypertension. A Scientific Statement From the American Heart Association. J Hypertension 47: 296308.

21. Saely CH, Risch L, Frey F, Lupi GA, Leuppi JD, Drexel H\& Huber AR 
(2009). Body mass index, blood pressure, and serum cholesterol in young Swiss men: an analysis on 56784 army conscripts. Swiss Med Weekly 139: 3536.

22. Faisal A\& Mukhtar A (2013). Prevalence of risk Factors of noncommunicable Diseases amongst female prisoners of Pakistan. J Eco Literat 14: 4.

23. Bandana S (2012). Diet and Lifestyle: its association with cholesterol levels among nomad tribal population of Rajasthan. Int J Med Biomed Resrch 1: 2.

24. Hermansen K (2000). Diet, blood pressure and hypertension. British J Nut 83:113-119.

25. Svetkey LP, Simons-Morton D, Vollmer WM, Appel LJ, Conlin PR, Ryan DH, Ard J \&Kennedy BM (1999). Effects of dietary patterns on blood pressure: subgroup analysis of the Dietary Approaches to Stop Hyper- tension
(DASH) randomized clinical trial. Archives Int Med 159: 285-293.

26. Bastola P, Pun CB, Koirala S \& Shrestha UK (2012). Fasting serum lipids and fundus changes in hypertensive patients. Nepal J Med Sci 1(2): 103-107.

27. Karanja NM, Obarzanek E, Lin PH, McCullough ML, Phillips KM, Swain JF, Champagne CM \& Hoben KP (1999). Descriptive characteristics of the dietary patterns used in the Dietary Approaches to Stop Hypertension; Trial: DASH Collaborative Research Group. $J$ AM Diet Assoc 99: S19-S27.

28. Appel L, Sacks FM, Carey VJ, Obarzanek E, Swain JF, Miller ER, Conlin PR, Erlinger TP, Rosner BA, Laranjo NM, Charleston J, McCarron P $\&$ Bishop LM (2005). Effects of protein, monounsaturated fat, and carbohydrate intake on blood pressure and serum lipids: results of the OmniHeart randomized trial. Jama 294: 2455-2464. 